\title{
Environmentally Induced Changes of Commercial Carbon Nanotubes in Aqueous Suspensions. Adaptive Behavior of Bacteria in Biofilms
}

\author{
Damián Rodríguez Sartori, Marcos Bertuola, Alejandro Miñán, Eduardo Gonik, Mónica C. Gonzalez, \\ and Mónica Fernández Lorenzo de Mele*
}

Cite This: ACS Omega 2021, 6, 5197-5208

Read Online

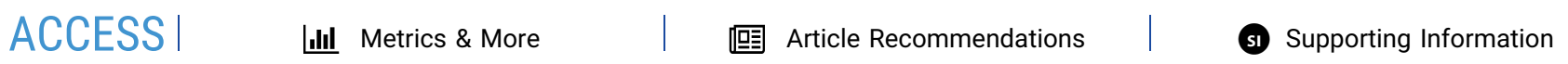

ABSTRACT: The effects of environmental factors such as sunlight irradiation and the presence of humic acid (HA) on the physicochemical properties of commercial multiwall carbon nanotubes (MWCNT) suspended in a simulated inorganic matrix (SIM) and their impacts on bacteria growing in biofilms were evaluated. Both solar irradiation and the presence of HA lead to the dissolution of adsorbed metals on the MWCNT, which are residues of synthesis catalysts. Also, preferential adsorption of certain HA components on the MWCNT induces important modifications in the aliphatic/aromatic relationship of HA components in solution and the generation and release of new moieties. Results demonstrated that the variation of such physicochemical parameters strongly affects the interactions of MWCNT with Pseudomonas aeruginosa sessile bacteria. Thus, the number of attached bacteria increased, and stress responses such as decrease in bacterial size were found in the presence of

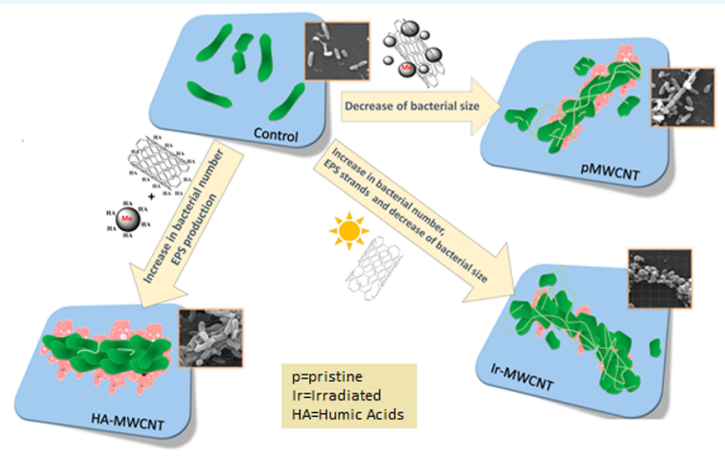
sunlight-irradiated MWCNT with a particular distribution of extracellular polymeric substances (EPS) strands. A shielding effect was observed when HA was added. It was concluded that physicochemical alterations caused by environmental conditions (with/without irradiation, presence/absence of HA) on MWCNT-containing SIM trigger distinctive adaptive behavior of bacteria in biofilms. This information must be taken into account in the development of biologically assisted treatments for organic metal co-contamination of MWCNT-containing media since MWCNT discharge alters the physicochemical properties and composition of the aqueous environment and the response of the biofilms that interact with it.

\section{INTRODUCTION}

Multiwall carbon nanotubes (MWCNT) are being vastly used in a broad range of applications in the electronic, pharmaceutical, and energy industries, due to their extraordinary stiffness and strength and superior thermal and electrical conductivity. ${ }^{1}$ Manufacturing procedures, multiple uses, and recycling of MWCNT and MWCNT-containing products may introduce unexpected properties to disposed MWCNT residues with emerging potential risks for the ecosystem and public health. ${ }^{2-5}$ Such is also the case of metallic catalyst residues from synthesis procedures frequently found in commercial MWCNT ${ }^{6}$ and MWCNT sorption of heavy metals and nonpolar organic compounds present in the aquatic media. ${ }^{7}$

Perturbations of the microbiological ecosystem by single (SWCNT) and MWCNT respectively) disposal may lead to a chain of biological events initiating severe damage to the environment. The antimicrobial effect of pristine SWCNT and MWCNT as well as carbon nanotube (CNT) composites of different diameters (between 1 and more than $200 \mathrm{~nm}$ ) at concentrations close to $100 \mathrm{ppm}$ against Gram-negative and
Gram-positive bacteria was recently reviewed and analyzed by Mocan et al. ${ }^{8}$ In view of the revised results, the authors concluded that neither the antibacterial mechanism nor the physical and chemical factors involved are yet completely elucidated. Many authors considered that SWCNT and MWCNT released or discharged into the environment perturb the vulnerable microbial system including their quorumsensing signals ${ }^{9}$ and could lead to alterations in nutrient cycling and degradation processes. ${ }^{10-12}$ Cell apoptosis with several impacts such as oxidative stress, DNA damage, and mitochondrial injury was reported, ${ }^{11,13-15}$ while other authors demonstrated that CNTs do not show acute toxicity but induce intracellular reactive oxygen species (ROS) in depend-

Received: October 20, 2020

Accepted: December 31, 2020

Published: February 17, 2021 
ence on contaminants. ${ }^{13}$ Such controversial results do not allow elucidating the whole impact of MWCNT disposal.

When the impact on the microbial community is evaluated, it must be considered that microorganisms can grow in suspension as planktonic cells or on biotic and abiotic surfaces forming structured colonies within a polymeric gel-like matrix, called biofilms. Importantly, biofilms have been considered as potential bioaccumulators of several sources of nanomaterials ${ }^{16}$ with different sensitivities to the type of the nanostructured engineered material. Notwithstanding biofilm importance, MWCNT toxicity was evaluated mainly in the planktonic way of life, ${ }^{17}$ and only few studies are reported about biofilms' or aggregates ${ }^{18}$ ways of life. Of these, some authors report no antibacterial activity by MWCNT, while others described a high inhibition of bacterial growth. ${ }^{19,20}$ Rodrigues and Elimelech $^{21}$ studied SWCNT toxicity and found a strong inhibition in the early stages of biofilm formation but lower toxicity on mature biofilms, thus suggesting that each stage of growth responds to the presence of SWCNT in a different manner. Also, the CNT surface chemistry has an important effect on toxicity, as demonstrated in assays with polymer nanocomposites containing CNT (CNT/PNC) which showed that PNC loading determines the rate at which the CNT/PNC surface becomes toxic for biofilms. ${ }^{22}$ In natural river water, a significant effect of organic coatings on CNT toxicity against biofilms was detected and associated with the production of ROS. $^{23}$

In natural aqueous environments, when the effects of MWCNT disposal is investigated, it should be considered that the dissolved organic matter and, particularly, humic acids (HAs) may condition the MWCNT interaction with the microbial community. HAs contain conjugated olefinic, aromatic, and phenolic-semiquinone-quinone structures of a wide spectrum with $-\mathrm{C}=\mathrm{O},-\mathrm{COOH},-\mathrm{OH},-\mathrm{NH}-$, $-\mathrm{NH}_{2}$, and $-\mathrm{N}$ functional groups capable of interacting with the MWCNT. $^{24}$ Organic substances contained in natural waters may also condition the behavior of microorganisms as their aggregates could precipitate onto surfaces of aquatic systems and disturb bacterial attachment and biofilm growth. $^{24,25}$

Another important factor to be considered in the analysis of the environmental impact of MWCNT is solar light irradiation as it may impact CNT physicochemical properties as demonstrated for SWCNTs. ${ }^{26}$ In a previous work, we have reported that residual metal catalysts and amorphous carbon contaminating the commercial MWCNT play an important role in the generation of MWCNT photoinduced chargeseparated states by UV light, leading to the fragmentation of oxidized graphene external walls and exposure of the lessoxidized inner walls. ${ }^{6}$ MWCNT doses of $10 \mathrm{ppm}$ are considered as the appropriate level to be assayed, since this concentration is close to $\mathrm{LD}_{50}$ in Daphnia magna, an established model organism for ecotoxicology testing of nanomaterials. ${ }^{27}$ The question that arises is if the physicochemical characteristics of MWCNT are altered by the environmental conditions and if these eventual alterations affect bacterial biofilms in different ways.

Changes in abiotic parameters such as total organic carbon (TOC), dissolved organic carbon (DOC), total phosphorus, and total nitrogen may result in microbial stress. ${ }^{28}$ Kang et al. particularly studied the effect of wastes in the nanoscale, such as CNTs, released in water and found damage in the membrane integrity and morphology of bacteria. ${ }^{29}$ Severe cell injuries including the release of nucleic acids into the liquid medium were reported. These authors also demonstrated that SWNTs may be more dangerous than MWCNT. On the other hand, some environmental factors affect the physicochemical properties of the CNT and, in turn, impact bacteria. ${ }^{30}$ In this line, considering that environmental factors such as irradiation and the presence of HAs may change the physicochemical properties of these nanostructures, it is interesting to investigate if the impact of the presence of MWCNT on the attached bacteria is increased when the MWCNT is environmentally modified.

In this article, we investigated the effect of environmental factors such as solar irradiation and the presence of HA on the physicochemical parameters of $10 \mathrm{ppm}$ MWCNT aqueous wastes and the distinctive adaptive behaviors of bacteria growing in biofilms. Particularly, growth rate, size and morphological changes of bacteria, and structural modifications and surface colonization by the biofilms, associated with these changes, were investigated. The purpose of this research is to contribute to the elucidation of the whole impact of these nanostructured anthropogenic wastes in biological systems having important consequences in biotechnological processes and in the whole ecosystem.

\section{RESULTS AND DISCUSSION}

2.1. HA/MWCNT System Characterization. Dynamic light scattering (DLS) measurements of $10 \mathrm{ppm}$ pristine MWCNT (pMWCNT) samples suspended in pure water yield hydrodynamic sizes of $329 \pm 42 \mathrm{~nm}$. When suspended in a simulated inorganic matrix (SIM) solution (0.11 M ionic strength), pMWCNT hydrodynamic sizes increased to values of $1125 \pm 97 \mathrm{~nm}$, as expected for an important increase in the ionic strength. ${ }^{5,31}$ The addition of $10 \mathrm{ppm} \mathrm{HA}$ to the latter suspensions yields even larger agglomerate sizes of $5560 \pm 50$ and $1335 \pm 258 \mathrm{~nm}$, evidencing the impact of the presence of $\mathrm{HA}$ in the aggregation process.

Possible specific interactions of MWCNT with the organic components of HA that could affect the relationship between the aromatic and aliphatic species of $\mathrm{HA}$ in the aqueous medium were evaluated considering the ratio between the absorbance at 465 and $665 \mathrm{~nm}\left(E_{465} / E_{665}\right.$ relationship) in the liquid phase after adsorption of HA on the nanotubes. These values were compared with that of the HA-containing medium without nanotubes.

$E_{465} / E_{665}$ has been related in the literature with the degree of condensation of aromatic carbon components of HAs. ${ }^{32}$ High $E_{465} / E_{665}$ values reflect the presence of large quantities of aliphatic structures and low quantities are indicative of abundant condensed aromatic structures, being this relationship inversely related to the degree of aromaticity.

Figure 1 shows that the relationship $E_{465} / E_{665}$ measured for different concentrations of HA, without the presence of nanotubes, is nearly constant. Unlikely, in the supernatant obtained after the exposure of MWCNT to different concentrations of $\mathrm{HA}$ followed by filtration, it can be noticed that $E_{465} / E_{665}$ increases with $\mathrm{HA}$ concentration up to saturation. According to previous reports, ${ }^{33,34}$ results can be interpreted bearing in mind that only molecules that are not adsorbed on the MWCNT are detected. Observed increasing $E_{465} / E_{665}$ values indicate that higher ratios of aliphatic structures than condensed aromatic moieties remain in solution after the adsorption process on MWCNT. Consequently, aromatic molecules are preferentially absorbed on 


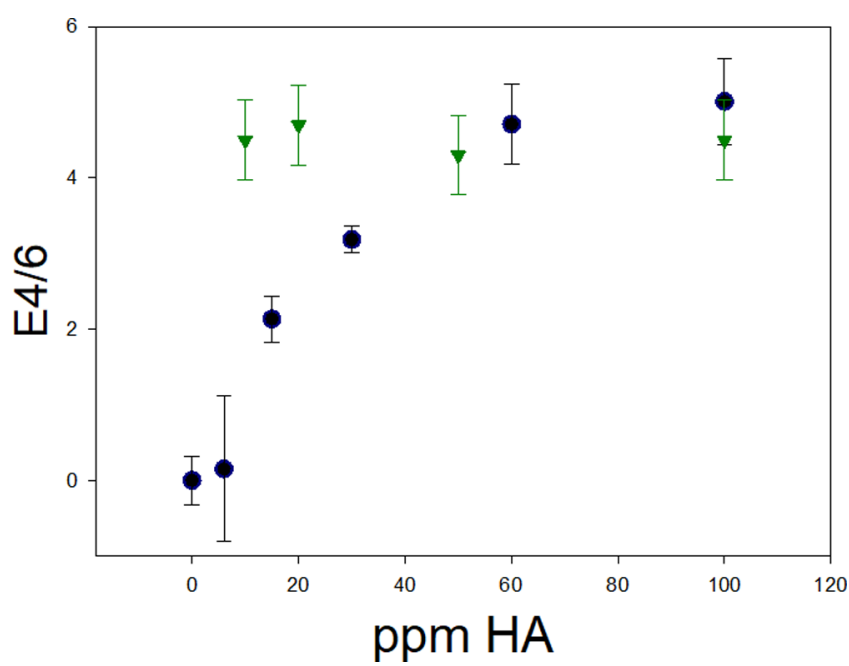

Figure 1. $E_{465} / E_{665}\left(E_{4} / E_{6}\right)$ relationship measured after HA adsorption on $10 \mathrm{ppm}$ of pMWCNT for different HA concentrations (blue dots). $E_{465} / E_{665}$ values for the different concentrations of HA solution without nanotubes were included as control (green triangles).

MWCNT, in agreement with reported studies ${ }^{33,34}$ suggesting that the adsorption of humic-like components on MWCNT is characterized by a preferential adsorption of higher molecular weight aromatic organic compounds probably involving $\pi-\pi$ interactions. Moreover, $\pi-\pi$ interactions between aromatic compounds adsorbed on different MWCNT might be a cause of the formation of larger MWCNT aggregates detected by DLS measurements in the presence of HA.

The Fourier transform infrared-attenuated total reflection (FTIR-ATR) spectra of pMWCNT, HA, and HA-MWCNT solid samples were obtained to evaluate the nature of adsorbed HA components on MWCNT. The FTIR spectrum of pMWCNT (see Figure 2) shows absorption bands, which may be attributed to surface oxidized groups and amorphous carbon introduced during the production process as those appearing at $3440 \mathrm{~cm}^{-1}\left(\mathrm{OH}\right.$ stretching $\left.{ }^{35}\right), 2925$ and 2860 $\mathrm{cm}^{-1}$ (asymmetric and symmetric $\mathrm{CH}$ stretching, respectively), and 1391 and $1097 \mathrm{~cm}^{-1}(\mathrm{C}-\mathrm{O}$ stretching in alcohols and

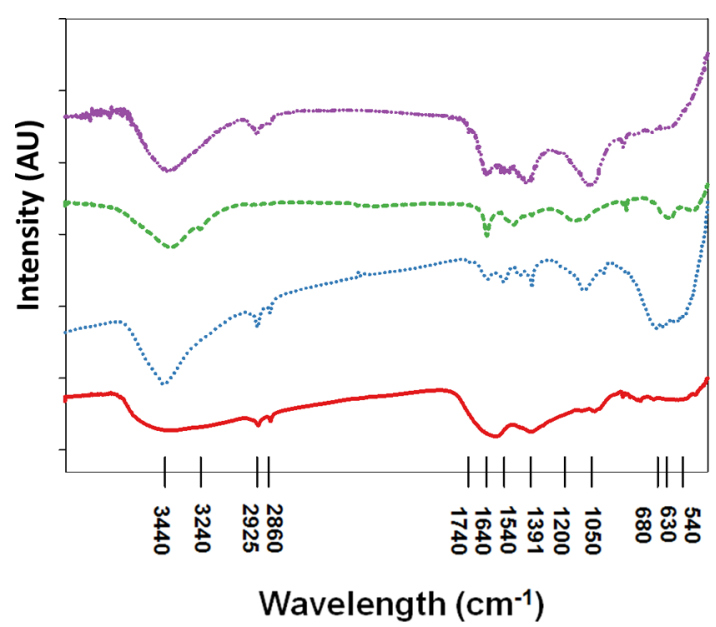

Figure 2. FTIR spectra. Left: HA [(-) red curve]; pMWCNT [(...) blue curve $]$; HA-MWCNT [(- - ) green curve $]$; and Ir-MWCNT $[(\cdot \cdots)$ violet curve $]$. phenols, respectively). Peaks around $1740 \mathrm{~cm}^{-1}$ due to stretching modes of carbonyl groups in carboxylic acids are of little significance. Small bands at 1640 and $1540 \mathrm{~cm}^{-1}$ may be assigned to conjugated $\mathrm{C}=\mathrm{C}$ stretching and aromatic bending, respectively. The broad intense bands in the 680$540 \mathrm{~cm}^{-1}$ range may be assigned to the stretching vibration of $\mathrm{Fe}-\mathrm{O}^{36}$ and $\mathrm{Al}-\mathrm{O}$ oxides ${ }^{37}$ attributed to the presence of remaining metal oxides used in the synthesis process.

The spectrum of HA-MWCNT solids showed peaks at 3240 and $1150 \mathrm{~cm}^{-1}$, not observed for pMWCNT. While peaks at $3240 \mathrm{~cm}^{-1}$ are assigned in the literature to $\mathrm{HO}$ groups interacting with a diamond surface, ${ }^{38}$ peaks at $1150 \mathrm{~cm}^{-1}$ may be assigned to phenyl ring $=\mathrm{C}-\mathrm{H}$ groups. The latter peak and that at $1640 \mathrm{~cm}^{-1}$ assigned to conjugated $\mathrm{C}=\mathrm{C}$ stretching strongly suggest an aromatic moiety-enriched surface. Moreover, peaks at $1592 \mathrm{~cm}^{-1}$ assigned to $\mathrm{COO}^{-}$in $\mathrm{HA}^{39}$ were not observed in HA-MWCNT spectra, while those in the 1100 $\mathrm{cm}^{-1}$ region assigned to aliphatic $\mathrm{HO}^{40}$ appeared in both samples. Altogether, the latter observations indicate that the more polar carboxylated components of HA were not significantly adsorbed on MWCNT.

Another important difference between the FTIR-ATR spectrum of pMWCNT and HA-MWCNT solids is the absence of peaks at $680 \mathrm{~cm}^{-1}$ and less intense ones at 630 $\mathrm{cm}^{-1}$ in the HA-MWCNT spectrum, thus suggesting the partial dissolution of adsorbed metal oxides upon adsorption of $\mathrm{HA}$ on the pMWCNT surface. Interestingly, the latter observation and the absence of adsorbed carboxyl-containing molecules, vide supra, seem to indicate that both metal ions and carboxyl moieties are retained in the aqueous phase in HAMWCNT suspensions. The observed tendencies are in line with literature reports indicating the preferential adsorption of hydrophobic parts of HA on CNTs through hydrophobic and $\pi-\pi$ interactions; meanwhile, the less-adsorbed hydrophilic fractions of HA having carboxyl groups can bind to the residual metal oxides adsorbed in the MWCNT external surface through ligand exchange and electrostatic attraction. ${ }^{41-43}$ Additionally, metal oxide nanoparticle dissolution rates may be significantly increased in the presence of HA-chelating molecules, as reported for zinc oxide and iron oxide nanoparticles. ${ }^{36}$

Voltamperometry experiments of pMWCNT in SIM suspensions in the presence and absence of $10 \mathrm{ppm} \mathrm{HA}$ and of pure $10 \mathrm{ppm}$ HA suspensions are shown in Figure 3. The voltamperograms show the reactivity of the dissolved organic products on the platinum electrode. Low reactivity on the $\mathrm{Pt}$ electrode was found for SIM and SIM-HA solutions. Similarly, low reactivity was found for the pMWCNT suspension in SIM. However, in the case of pMWCNT suspended in $10 \mathrm{ppm} \mathrm{HA}$ SIM solutions, high anodic peaks were detected during the anodic and cathodic scans close to 0.5 and $0.3 \mathrm{~V}$, respectively. These current density contributions reveal a high interaction of pMWCNT with HA, leading to species that can be oxidized on the $\mathrm{Pt}$ surface. Because of such interactions, there is an important change in the dissolved organic-inorganic composition of the SIM-HA solution in the presence of pMWCNT. Nonadsorbed low-molecular-weight organic compounds may be complexed with dissolved metals from the nanotubes.

Altogether, the discussed results seem to support the fact that the effect of HA on pMWCNT SIM suspensions is that of partially dissolving adsorbed metal catalysts remaining from the MWCNT synthesis procedures by the formation of complexes with low-molecular-weight polar components of 


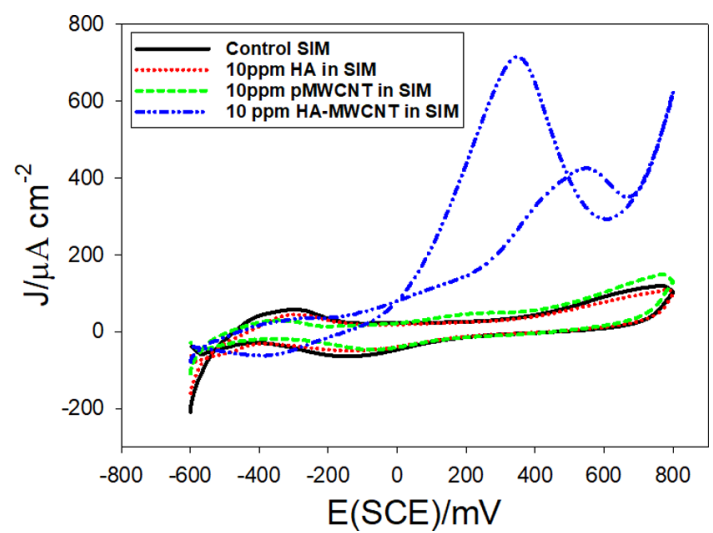

Figure 3. Cyclic voltammetry performed with a Pt electrode at $1 \mathrm{mV}$ $\mathrm{s}^{-1}$ in solutions containing the following: (-) SIM solution; (.....) 10 ppm of HA in SIM; (- - ) 10 ppm of pMWCNT suspended in SIM; $(\ldots \ldots \ldots) 10 \mathrm{ppm}$ of pMWCNT and $10 \mathrm{ppm}$ of HA in SIM suspension.

HA. High-molecular-weight aromatic components of HA are preferentially adsorbed on the MWCNT surface. In fact, it is well established in the literature that $\mathrm{Al}$ and $\mathrm{Fe}$ ions are dissolved and complexed by HA and fulvic acid. ${ }^{44-46}$

2.2. Suspensions of Solar-Irradiated pMWCNT in SIM. pMWCNT suspensions in SIM were irradiated at Tw30 = 52 min (Ir-MWCNT), as described in the experimental part. DLS measurements of solar-irradiated samples showed aggregates of $123 \pm 32 \mathrm{~nm}$ hydrodynamic radii coexisting with $484 \pm 57 \mathrm{~nm}$ ones. Since pMWCNT SIM suspensions' aggregate sizes were of $1125 \pm 97 \mathrm{~nm}$, a debundling effect of solar irradiation on pMWCNT samples takes place. To obtain information on the effect of solar light irradiation on pMWCNT suspensions, irradiated samples were filtrated through $45 \mu \mathrm{m}$ pore membranes and the solid phase was washed with distilled water and dried overnight at $80{ }^{\circ} \mathrm{C}$. The filtrate was stored in the dark until further FTIR-ATR analysis.

FTIR-ATR spectrum of Ir-MWCNT solids (see Figure 2) shows absorption bands attributed to surface oxidized groups as those appearing at $3440,1391,1097$, and $1150-1050 \mathrm{~cm}^{-1}$ as well as small bands at 1640 and $1540 \mathrm{~cm}^{-1}$ assigned to conjugated $\mathrm{C}=\mathrm{C}$ stretching and aromatic bending, respectively, in line with those observed for pMWCNT. However, the broad intense bands in the $680-540 \mathrm{~cm}^{-1}$ range of the pMWCNT spectrum assigned to metal oxides are of little significance in Ir-MWCNT solids. These observations seem to support a significant desorption and release of surface residual metals following solar irradiation in artificial water suspensions, in line with the results previously reported by our group on the effect of $350 \mathrm{~nm}$ light irradiation on MWCNT. ${ }^{6}$

In fact, inductively coupled plasma-mass spectrometry (ICP-MS) analysis of the liquid phase of the solar-irradiated suspensions and those of pMWCNT suspensions stored in the dark confirmed that $\mathrm{Al}, \mathrm{Co}$, and $\mathrm{Fe}$ were released from the nanotubes toward the solution upon irradiation as shown in Figure 4. Among them, released $\mathrm{Al}$ ions in the irradiated samples are 55 times higher than those released by the pMWCNT stored in the dark.

Interestingly, solar irradiation of the pMWCNT in SIM suspensions leads to a reduction of the oxygen demand from 1000 ppm molecular oxygen to ca. 500 ppm upon Tw30 $=52$ min irradiation period. Oxygen demand is an indirect quantification of the amount of species that were oxidized during solar irradiation of the nanotube suspensions in SIM.

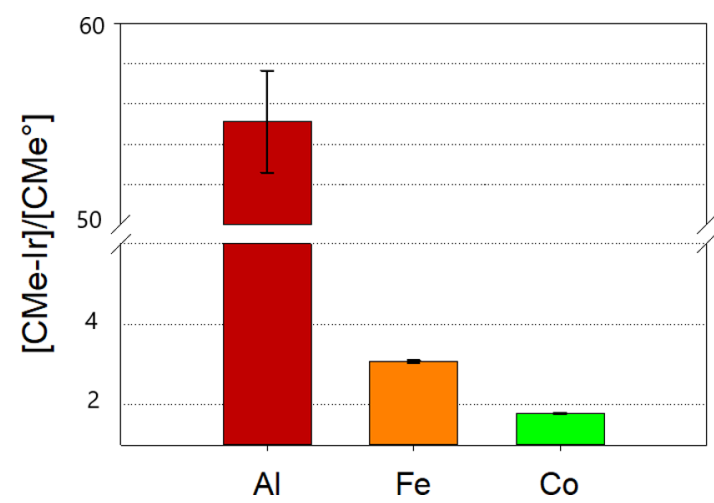

Figure 4. Relationship between the amount of metals released upon solar irradiation of pMWCNT SIM suspensions (CMe-Ir) and those of pMWCNT suspensions stored in the dark for an equivalent period of time $\left(\mathrm{CMe}^{\circ}\right)$.

All in all, the disposal of MWCNT in natural environments leads to important changes in the oxygen demand that may affect the biological environment.

TOC present in the liquid phase of SIM suspensions containing pMWCNT before and after solar irradiation varies from 0.9 to $15.2 \mathrm{ppm}$, respectively. An increase of TOC coupled to a decrease of oxygen demand strongly points to the oxidation of $\mathrm{C}$ structures during solar irradiation that are released to the liquid phase of the suspension.

Thus, the discussed results seem to support the fact that the effect of solar irradiation on pMWCNT suspensions in SIM is that of dissolving surface-adsorbed metal catalysts remaining from synthesis procedures and of oxidizing pMWCNT $\mathrm{sp}^{3} \mathrm{C}$ which gets dissolved in the liquid phase of the suspension.

All in all, physicochemical evaluation revealed that the addition of MWCNT to the saline medium significantly changes the composition and the properties of the medium by changing the aliphatic/aromatic relationship due to adsorption processes and by increasing the oxygen demand and the concentration of metals. Solar irradiation and the presence of HA significantly modify the surface of the MWCNT changing its composition and releasing metal ions and highly oxidized C moieties to the suspension liquid phase. The strong modification of the composition and properties of the aqueous media and of the nanotubes impact the development of a microbial biofilm system as described in the following sections.

2.3. Alteration of MWCNT by Environmental Conditions: Impact on Growth, Distribution, and Morphology of Early Bacterial Biofilms. Despite being less frequently investigated than their planktonic counterparts, bacteria irreversibly attached on surfaces forming early biofilms usually show interesting responses to environmentally aggressive agents and released wastes that alter the aqueous medium. Thus, it is interesting to analyze the impact of MWCNT, HA-MWCNT, and Ir-MWCNT on early biofilms.

Scanning electron microscopy (SEM) images of the biofilms grown under different conditions studied yield information on the bacterial distribution on the glass surface, extracellular polymeric substances (EPS) distribution, and microbial size. It can be noticed that bacteria in the control samples (see Figure 5B) are isolated and some of them were dividing. Besides, there are small groups with low quantity of EPS. The characteristics of the control biofilm are in line with the condition of nutrient restriction used in the experiment to emulate the natural environments, since it is known that this 

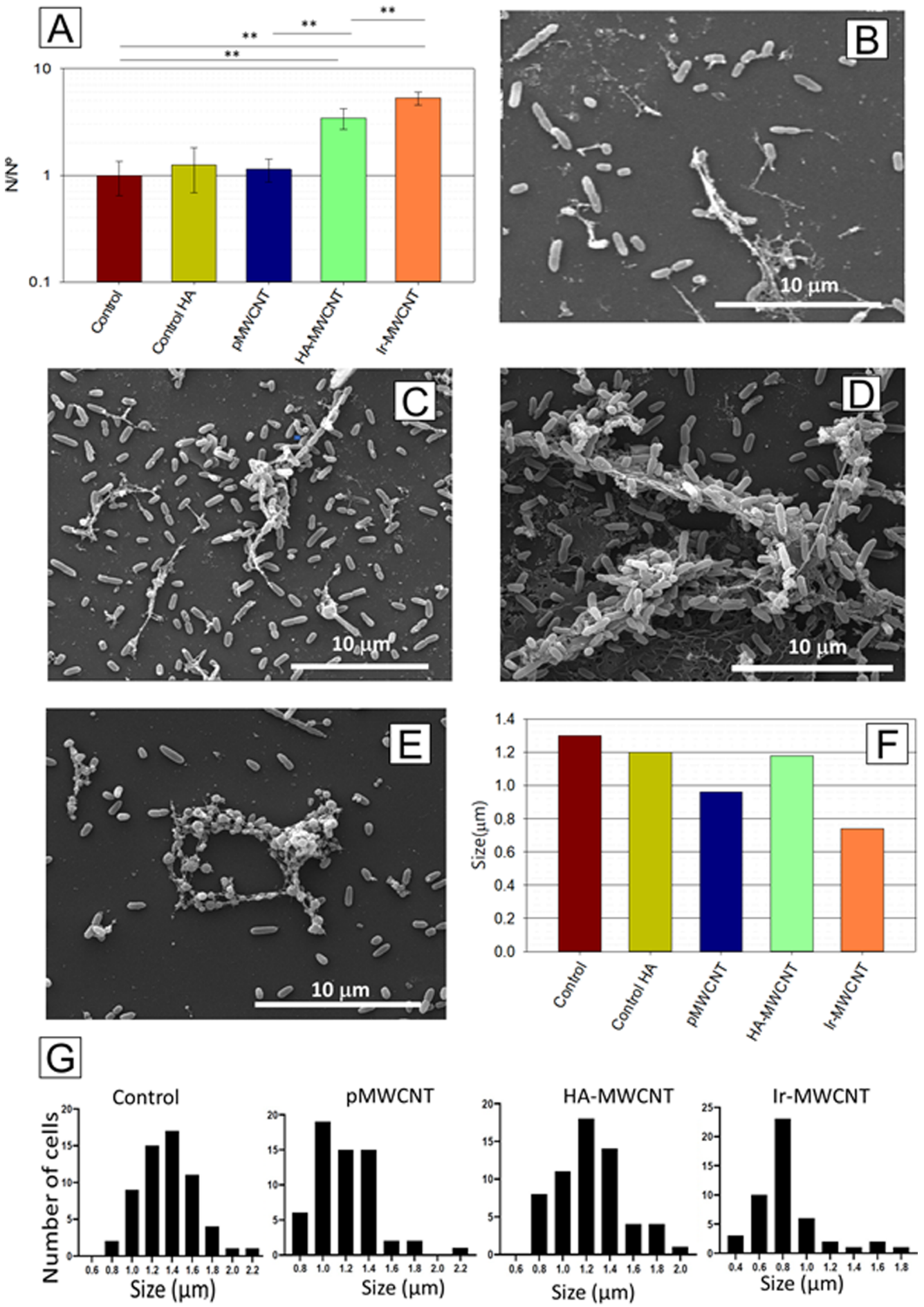

Figure 5. (A) Relationship $\left(N / N^{\circ}\right)$ between the number of cells before $\left(N^{\circ}\right)$ and after $(N)$ being exposed to the presence of the following: (brown column) diluted NB denoted as control; (yellow column) NB + 10 ppm of HA; (blue column) NB + 10 ppm of pMWCNT; (green column) NB + 10 ppm of HA-MWCNT; and (green column) NB + 10 ppm of Ir-MWCNT solids. Statistical analysis of the significance of the differences: $(* *) p$ $<0.01$ and $\left(^{*}\right) p<0.05$. SEM microphotographs of attached bacteria: (B) control; (C) pMWCNT; (D) HA-MWCNT; (E) Ir-MWCNT solids. (F) Median diameter of the cells grown under the same conditions indicated in (A). In Figure S2, the relative cumulative frequency plots used to obtain the median value are shown. (G) Size distribution of the cells for each condition.

condition leads to a weak biofilm structure. ${ }^{47,48}$ The analysis of bacterial size show a Gaussian distribution of sizes centered around $1.3 \mu \mathrm{m}$.

To complement the information of plate count measurements and SEM observations, epifluorescence microscopy was performed. It can be seen (Figure S3, Supporting Information) that, in the case of the control, the area covered by EPS and cells is green, revealing the healthy state of the cells. Low amounts of EPS were found, in agreement with SEM images shown in Figure 5B.

2.3.1. Effect of the Addition of PMWCNT and HApMWCNT. The number of bacteria in biofilms grown in the 
presence of $10 \mathrm{ppm}$ of either pMWCNT or HA alone, Figure $5 \mathrm{~A}$, was not affected. However, a slight but statistically significant enhanced growth with respect to the control was observed in the presence of $10 \mathrm{ppm}$ pMWCNT that has been in contact with HA (HA-MWCNT).

Formation of small groups of microorganisms was detected in the pMWCNT-containing medium (Figure 5C). The histograms show a non-Gaussian distribution of bacterial sizes with a maximum at $1.0 \mu \mathrm{m}$ (Figure 5F), lower than that of the control. Again, when the median value of the bacterial size of the control is compared with that of the pMWCNT assay, lower sizes are observed (Figure S2), indicating that bacteria were stressed by the presence of pMWCNT and, consequently, reduced their volume. Epifluorescence microscopy showed another surprising result (Figure S3): when pMWCNT were added to the culture medium, notwithstanding that the number of attached bacteria did not increase (Figure 5A), the fluorescent area was 20 times larger than the control area (relationship between covered areas $A_{\mathrm{pMWCNT}} /$ $\left.A_{\text {control }}^{\circ}=20.01 \pm 6.96\right)$, indicating a higher biofilm coverage under this condition. Importantly, orange fluorescent areas were observed, probably related with a more toxic environment than the control condition.

After the contact of MWCNT with HA (HA-MWCNT), an increase in the number of bacteria and in bacterial size (median value $=1.18 \mu \mathrm{m}$, Figure S2) in relation to pMWCNT was observed. The formation of dense three-dimensional (3D) biofilm structures was noticed, revealing changes in bacterial response that lead to a particular distribution of EPS with a shielding and protective effect that seems to reduce the impact of MWCNT (Figure 5D). HA-MWCNT depict larger agglomerates of nanotubes and cells seem to be gathered around the nanostructures. These nanostructures may offer nutrients that also enhance the bacterial growth as, according to the physicochemical characterization, HA components are adsorbed on the nanotubes. Moreover, according to physicochemical results previously shown, complexes with dissolved metals seem to be formed and some of them remain on the HA-MWCNT surface. They may act either as an electron shuttle and mediate the biological cycle that may be enhanced by dissolved $\mathrm{Fe}^{49}$ or as a reducer of the aluminum bioavailability. ${ }^{50}$ As expected, epifluorescence microscopy showed that the area covered by the biofilm was even higher $\left(A_{\mathrm{HA}-\mathrm{MWCNT}} / A_{\text {control }}^{\circ}=66.65 \pm 23.22\right.$ times $)$ in the case of HAMWCNT, in agreement with the better nutrient condition. Similar relationships of biofilm areas were reported when biofilms growing in a rich medium and in a poor one were compared. $^{47,48}$ Unlike pMWCNT assays, the green fluorescence disclosed in the HA-MWCNT condition demonstrates the protective role of HA adsorbed on MWCNT.

In fact, it is well known in the literature that there is an overproduction of EPS by microorganisms in the presence of CNTs and organic components, which involves physicochemical adsorption of organic compounds and hydrophobic interactions. ${ }^{51}$ It has been reported that EPS can protect bacteria through sequestering nanoparticles, thereby reducing the particle-specific toxic activity, particularly those related to the release of toxic metal ions. ${ }^{52}$ There is a general agreement in considering that there is an important role of the EPS matrix as a protective barrier for metal adsorption on bacterial cell walls. $^{53-55}$ The presence of an EPS layer is likely to result in major differences in cell electrophoretic mobility as a function of $\mathrm{pH}$ and ionic strength, related to a comparable EPS-free cell. $^{56}$

2.3.2. Impact of Solid Phase of Irradiated MWCNT Solids. Biofilm development was also investigated in the presence of sunlight-irradiated MWCNT solids (Ir-MWCNT, see Table 1)

Table 1. Different Conditions of MWCNT and Their Acronyms $^{a}$

\begin{tabular}{ll}
\multicolumn{1}{c}{ acronym } & \multicolumn{1}{c}{ condition } \\
control & SIM without MWCNT \\
control-HA & SIM + 10 ppm HA without MWCNT \\
pMWCNT & $\begin{array}{l}10 \text { ppm pristine MWCNT (as received, without further } \\
\text { purification) in SIM suspension }\end{array}$ \\
HA-MWCNT & $\begin{array}{c}10 \text { ppm pristine MWCNT with } 10 \mathrm{ppm} \text { of HA in SIM } \\
\text { suspension }\end{array}$ \\
Ir-MWCNT & $\begin{array}{c}\text { irradiated pMWCNT (Tw30 }=52 \mathrm{~min} \text { ) solids filtered from } \\
\text { the aqueous phase solution in SIM suspension }\end{array}$ \\
${ }^{a}$ See also Figure S1 of Supporting Information.
\end{tabular}

that were suspended in the culture medium to evaluate the impact of MWCNT devoid of the adsorbed impurity metals and $\mathrm{sp}^{3} \mathrm{C}$ defects present in pMWCNT. To that purpose, $2 \mathrm{~h}$ biofilmed glasses were incubated at $31^{\circ} \mathrm{C}$ in the presence of 10 ppm suspensions of Ir-MWCNT solids that, according to DLS results of previous section, show lower hydrodynamic radii.

A marked increase in the number of bacteria in biofilms grown in the presence of $10 \mathrm{ppm}$ of Ir-MWCNT solids is observed (Figure 5D) compared to controls (Figure 5A). However, SEM images clearly show that this increase in the number of bacteria is accompanied by a drastic reduction in the size of bacteria $(0.74 \mu \mathrm{m}$, Figure $5 \mathrm{D}, \mathrm{F})$. However, the lower reduction in bacterial size is observed again in the presence of HA (Figure S2).

SEM microphotographs also show that Ir-MWCNT solids induce the formation of thin EPS strands that bind bacteria to each other and to the solid substrate depicting a biofilm matrix of particular characteristics and denoting the high stress level of bacteria.

In line with the observed morphological changes, it has been reported that under stress conditions, bacteria usually reduce their size. ${ }^{57}$ Interestingly, the number of attached bacteria in the presence of Ir-MWCNT is markedly higher than that of the control. Consistently, it was also reported that when the cellular damage leads to bacterial death and the organic wastes remain in the EPS matrix, they function as a nutrient source for the biofilm development and increases the growth rate of the cells. $^{21}$ Epifluorescence images of biofilms with Ir-MWCNT showed the largest average areas $\left(A_{\mathrm{Ir}-\mathrm{MWCNT}} / A_{\text {control }}^{\circ}\right)$, more than 120 times than the control, in line with the highest number of cells detected by plate count. However, it should be mentioned that there is a high variation between the measurements of covered areas that leads to a high standard deviation of these data. The growth enhancement in toxic environments has been related to the extracellular enzymes provided by EPS, able to metabolize dissolved biopolymers. It has been hypothesized that cell lysis followed by the consequent EPS decomposition may favor the development of the biofilm creating new pores and channels that improve nutrient access ${ }^{58-60}$ being cell detritus possible additional nutrients. Again, the orange color of the biofilmed areas suggests that a toxic environment affects the health of the cells. Changes in the EPS composition have also been detected under stress environments. It is believed that they are 
characterized by a higher production of Psl polysaccharide in relation to the other EPS components. ${ }^{61}$

An interesting result obtained by epifluorescence microscopy confirmed the protective nature of HA. When the IrMWCNT was previously exposed to HA and then added to the bacterial culture (Ir-HA-MWCNT), the fluorescent areas, unlike the full-orange surfaces observed in the case of IrMWCNT, showed green zones among the orange regions (Figure S4). The SEM image revealed a high surface colonization that was characterized by an EPS strand net notoriously more compact than for Ir-MWCNT (Figure S3). The presence of EPS strands was also detected in SEM microscopies corresponding to Pseudomonas in stress environments under sublethal concentrations of antimicrobials. Similar complex and reproducibility of the structural motifs were found in other Pseudomonas biofilms and seem to be the result of an organized assembly and not local and particular bacterial associations. $^{62}$

The bacterial size distribution is also shown on the right side (Figure S4c). The cumulative relative frequency curve corresponding to Ir-HA-MWCNT is also included in Figure S2 to show the shielding effect of $\mathrm{HA}$, since the median value of the bacterial lengths $(0.81 \mu \mathrm{m})$ is higher than that of IrMWCNT $(0.74 \mu \mathrm{m})$.

It is known that EPS consists of mainly polysaccharides, proteins, nucleic acids, and lipids that provide mechanical support to biofilms and mediate the adhesion processes that lead to the formation of the polymeric scaffold where microorganisms are temporally immobilized. ${ }^{58}$ The different conditions analyzed in Figures 5, S3, and S4 show changes in the EPS coverage, distribution, and structure. It was previously informed that changes in composition were observed for Pseudomonas under the stress environment generated by the presence of subinhibitory concentrations of antimicrobials. Protein and total lipid detections increased under these conditions, $^{62}$ revealing that they are associated with a protective effect of EPS against the adverse environment, since the sheltered membrane was able to remain undamaged. Thus, the ability of altering EPS properties seems to be linked to bacterial resistance to stress conditions. ${ }^{60}$ Results showed a dense net of EPS strands that can be noticed in the presence of the nanostructures (Figure S3), highlighting the important influence of HA in bacterial response because it favors the production of these polymeric substances, reducing bacterial stress (higher HA-MWCNT bacterial size than Ir-MWCNT, Figures S2 and S3). Thus, changes in EPS composition under these dissimilar situations will be the focus of future studies.

The effect on the EPS structure, distribution, amount, and composition is important but not less relevant are the alteration of cell size when MWCNT are present. In agreement with our results, it has been shown that stress also leads to alterations in Pseudomonas morphology, leading to shorter and/or thinner cells. ${ }^{63-67}$ The effects on membrane integrity and bacterial morphology by nanostructured wastes were also reported by Kang et al. ${ }^{29}$ with severe cell injury in the case of nanotubes.

All in all, it is worth remarking that literature reports associate the modifications of the biofilm growth by pollutants in the nanoscale with a sequence of events that mainly depends on the concentration and pollutant properties as well as on the exposure time..$^{21,51,68}$ According to our observations, sunlight irradiation leads to changes in surface compositions of nanotubes, leading to alterations in their hydrophobicity.
Based on the observations, we propose the following model: in the first stages, the highly hydrophobic nanotubes interact with the cell membrane causing bacterial damage and the release of an intracellular material, which serves as a carbon source and facilitates the adhesion and growth of new bacteria. Therefore, modifications on the carbon surface by irradiation might have a toxic effect at very early stages of bacterial attachment, leading to a decrease in their size but promoting bacterial proliferation. When Ir-MWCNT are previously exposed to HA, signs of toxicity reduction are detected since the size of bacteria increases, a production of EPS strands takes place and a compact-protecting EPS matrix is formed (Figure S3). These observations are in line with previously reported assays with reduced graphene oxide, whose toxicity decreases in the presence of high amounts of EPS. ${ }^{69}$

2.4. Impacts on the Environment and Biotechnological Systems. Results show that the presence of $10 \mathrm{ppm}$ pristine, HA-absorbed, and irradiated MWCNT in saline aqueous media generates environmental alterations in aqueous systems, which are as follows: increase of rate of oxygen demand, formation of MWCNT aggregates of different sizes, modification of the MWCNT surface, and the release of residual synthesis metals $(\mathrm{Fe}, \mathrm{Co}, \mathrm{Al})$. In contrast, the adsorption of HA on MWCNT surfaces leads to the change of the media composition due to the preferential adsorption of high-molecular-weight organic substances that seems to induce the formation of new organic moieties that were electrochemically detected.

Biological assays show that bacteria in biofilms sense the physicochemical changes and respond accordingly using different strategies that include adaptive changes in duplication rate, morphology, size, and EPS distribution that leads to alterations in the associated biomass.

These effects should be considered in technological systems such as biologically assisted treatments of CNTs-containing wastewater because of the important impact of the variables previously mentioned in the activity of the microbial community. With respect to drinking water supplies, it should be taken into account that due to the MWCNT discharge in natural systems and their exposure to irradiation and HAs, several effects could be noticed: variation in the concentration of natural organic components due to adsorption and oxidation processes, changes in the fraction of hydrophilic/hydrophobic compounds, and increasing trace level relationships of organic pollutants and metals. They are potential hazards for public health and the environment.

Another bioengineering process that may be altered is bioremediation. Bioremediation is an effective method for cleaning up the widespread anthropogenic pollution. This process employs a living organism to either degrade organic pollutants into innocuous end-products or immobilize metals. $^{70}$ It is known that $\mathrm{Al}$ ions severely influence the $\mathrm{Fe}$ metabolism of Pseudomonas species since Al can substitute Fe and render some proteins/enzymes processes ineffective. The toxic action of $\mathrm{Al}$ is linked to the dysfunction of $\mathrm{Fe}$ homeostasis. $^{70}$ Thus, $\mathrm{Al}$ ions induce changes that are associated with oxidative stress that leads to DNA damage or alterations in the Krebs cycle and production of antioxidants. According to our results, these ions are easily available when MWCNT are discharged in natural environments and enhanced by the presence of humic substances. It has been reported that in the presence of aromatic molecules, $\mathrm{Al}$ ions may also cause the accumulation of their degradation 
intermediates interfering in the metabolism of these aromatic compounds. ${ }^{70}$ Consequently, when bioremediation is applied, the physicochemical changes and interferences produced by MWCNT discharge should be taken into account since they lead to changes in the aromatic/aliphatic relationships of organics in the aqueous media and also facilitate the presence of metal cocontaminants and metal ions such as $\mathrm{Al}$ ions that, in turn, alter the biodegradation of the organic pollutant by bacteria.

\section{CONCLUSIONS}

Our results clearly demonstrate that MWCNT may be strongly transformed by environmental variables such as sunlight irradiation and the presence of $\mathrm{HA}$ and, in parallel, physicochemical properties of the aqueous media after MWCNT discharge is also drastically modified. Among these alterations, we have detected the following: modifications of the size of agglomerates, of the MWCNT surface composition, and of the area available for reactions; changes in the aliphatic/ aromatic relationships and generation of new moieties by adsorption and oxidation processes; and alterations of oxygen demand, DOC, and dissolution of metals ( $\mathrm{Fe}, \mathrm{Co}, \mathrm{Al}$ ). Thus, low-molecular-weight organic products released to the aqueous media may interact with residual synthesis metals $(\mathrm{Fe}, \mathrm{Co}, \mathrm{Al})$ and form metal complexes with carboxyl-containing lowmolecular-weight aliphatic components of HA.

Results also revealed that adaptive behaviors are developed by bacteria in response to physicochemical changes of the environment: enhanced surface colonization by biofilms, morphological and size changes of bacteria, and modifications in bacterial duplication rate and in the distribution pattern (two-dimensional or 3D bacterial biofilm growth). Changes in the EPS composition and amount are probably produced and will be the focus of future studies. In all cases, after exposure of the nanotubes to the different conditions assayed (pMWCNT, HA-pMWCNT, Ir-MWCNT), the size of the attached bacteria changed in relation with the control and the smaller sizes corresponded to irradiated nanostructures. Additionally, a higher number of cells of smaller size than the control joined by thin strands of EPS were found in Ir-MWCNT assays. The desorbed organic moieties from the MWCNT surface and bacterial detritus may be trapped by EPS and become available food for bacteria in biofilms with the consequent enhancement of biofilm growth. EPS production and 3D biofilm structures seem to be favored in the case of biofilms growing in HAcontaining media (HA-MWCNT and Ir-HA-MWCNT) that seem to induce the complexation of toxic ions such as $\mathrm{Al}$ ions. These diverse alterations may act as a first link in the chain of successive environmental changes.

All in all, results demonstrate that important changes of physicochemical parameters of aqueous media related to MWCNT disposal are induced. These alterations are strongly dependent on irradiation and/or the presence/absence of HA and condition the toxicity of MWCNT in microbiologically active media, showing different impacts in microbial proliferation and metabolic activity.

The observed changes must be taken into account when biologically assisted treatments are applied in MWCNTcontaining aqueous media since the alterations of the aromatic contents in the liquid phase, TOC, and oxygen demand as well as the presence of $\mathrm{Al}$ ions may severely modify the bioengineering process due to the modifications in the microbial response and the biomass amount.

\section{EXPERIMENTAL SECTION}

4.1. Materials. Commercial MWCNT (denoted as pMWCNT) were Nanocyl NC7000 industrial grade, C purity $90 \%$, diameter $9.5 \mathrm{~nm}$, length $1.5 \mathrm{~mm}$, and specific surface area $475 \mathrm{~m}^{2} \mathrm{~g}^{-1}$. The content of main impurities determined by energy-dispersive $\mathrm{X}$-ray analysis was $\mathrm{Al}$ (5.9 wt \%), Fe (0.5 wt $\%)$, and Co (0.2 wt \%). Solutions were prepared by suspending $10 \mathrm{mg}$ of MWCNT in $1000 \mathrm{~mL}$ of pure water or in $1000 \mathrm{~mL}$ of simulated natural inorganic matrix (SIM) at room temperature.

The composition of the saline solution used to simulate natural waters' inorganic matrix maintains the ion proportion of Puelche Aquifer ${ }^{91}$ but not its overall concentration. The concentrations of each ion in the SIM solution were as follows: $678.8 \mathrm{ppm} \mathrm{Cl}{ }^{-}, 400 \mathrm{ppm} \mathrm{SO}{ }_{4}{ }^{2-} ; 21.2 \mathrm{ppm} \mathrm{NO}_{3}{ }^{-} ; 206.6 \mathrm{ppm}$ $\mathrm{Na}^{+}$; $37.8 \mathrm{ppm} \mathrm{K} \mathrm{K}^{+}$; $555 \mathrm{ppm} \mathrm{Ca}^{2+} ; 716.6 \mathrm{Mg}^{2+}$. The ionic strength of the SIM solution was $0.1126 \mathrm{M}$ and $\mathrm{pH}$ was adjusted to 8.5. The following salts were used without further purification: $\mathrm{MgSO}_{4} \cdot 7 \mathrm{H}_{2} \mathrm{O}$ (99.5\% AppliChem), $\mathrm{MgCl}_{2} \cdot 6 \mathrm{H}_{2} \mathrm{O}$ (99\% Cicarelli), $\mathrm{Na}_{2} \mathrm{CO}_{3} \cdot \mathrm{H}_{2} \mathrm{O}$ (99\% Timber), $\mathrm{KCl}$ (99\% Biopack), $\mathrm{NaNO}_{3}$ (99\% Biopack), $\mathrm{CaCl}_{2}$ (99\% Anhedra), $\mathrm{NaCl}$ (99\% Anhedra), AcNa (99\%, Sigma-Aldrich).

HA sodium salts were purchased from Sigma-Aldrich and used without further purification. A concentration of $10 \mathrm{ppm}$ HA was employed in all the experiments. All aqueous solutions were prepared with deionized ultrapure water (Milli-Q purified, 18.2 $\mathrm{M} \Omega \mathrm{cm}$ and $6 \mathrm{ppb}$ TOC).

4.2. Sunlight Irradiation. The experiments of sunlight irradiation were done using a complex $4 \mathrm{~L}$ cylindrical parabolic reactor ECOSYSTEM-SOLARDETOX ARCADUS 2005/ 0.25 . The equipment has a peristaltic bomb PanWorld 5PX$\mathrm{Z}$ and an ACADUS 85 radiometer and is capable of measuring the real-time radiation $\left(\mathrm{W} \cdot \mathrm{m}^{2}\right)$ and the accumulated radiation $(\mathrm{W} \cdot \mathrm{h})$. Since radiation depends on the climate and the season of the year, we use the normalized time of illumination (Tw30) that assumes that in a sunny middle day, the mean $2 \mathrm{~h} \mathrm{UV}$ radiation is $30 \mathrm{~W} / \mathrm{m}^{2}$. Each time was corrected using the following equation

$$
t_{\mathrm{w}, n}=t_{\mathrm{w}, n-1}+\Delta t_{n}\left(\mathrm{UV} \cdot V_{\mathrm{i}}-30 V_{\mathrm{T}}\right) \quad \Delta t_{n}=t_{n}-t_{n-1}
$$

where $t_{n}$ is the irradiation time of each experiment " $n$ ", UV is the average value of the ultraviolet irradiation detected by the radiometer during $\Delta t_{n}$, and $V_{\mathrm{i}}$ and $V_{\mathrm{T}}$ are the irradiated volume $(1.36 \mathrm{~L})$ and the total volume of the reactor, respectively.

4.3. Experimental Protocols to Obtain Treated MWCNT. Different conditions of the nanotubes were used in the experiments. Ir-MWCNT was obtained from $4 \mathrm{dm}^{3}$ of a 10 ppm pMWCNT in SIM suspensions (in the absence and presence of $10 \mathrm{ppm} \mathrm{HA}$, respectively) irradiated during Tw30 $=52 \mathrm{~min}$. Subsequently, the acronyms used to denote the different types of MWCNT obtained after the different treatments are listed in Table 1.

4.4. HAs $E_{465} / E_{665}$ Absorbance Relationships. For the absorption experiments, HA solutions of different concentrations were added to $10 \mathrm{ppm}$ of pMWCNT in an aqueous SIM solution until the absorption equilibrium was reached. Then, the samples were subsequently centrifuged at $6000 \mathrm{G}$, and the supernatant was analyzed using a double-beam Shimadzu UV-1800 spectrophotometer in a $1 \mathrm{~cm}$ quartz cuvette at a scan rate of $300 \mathrm{~nm}$ min and $1 \mathrm{~nm}$ bandpass. The $E_{465} / E_{665}$ relationship was calculated after measuring the absorbance values at 465 and $645 \mathrm{~nm}$. 
4.5. Characterization Techniques and Methodology. Oxygen demand measurements were made using a Merck DQO kit. To that purpose, $1 \mathrm{~mL}$ of previously irradiated samples was added to the flask containing the reactants. Then the samples were incubated at $148{ }^{\circ} \mathrm{C}$ for $2 \mathrm{~h}$ and cooled at room temperature. The amount of oxygen demand was estimated using a Spectroquant spectrophotometer that automatically transforms the absorbance in ppm of oxygen.

DLS results were obtained at $25.0 \pm 0.1{ }^{\circ} \mathrm{C}$ with a Malvern Zetasizer Nano (Malvern Instruments; UK) after appropriate dilutions of MWCNT suspensions. Each system was analyzed three times.

Semiquantitative analysis of $\mathrm{Al}, \mathrm{Co}$, and $\mathrm{Fe}$ released after the solar irradiation was performed by ICP-MS using a PerkinElmer Optima 7000DV using pMWCNT and IrpMWCNT liquid phase samples. To perform the measurements, the samples containing $10 \mathrm{ppm}$ of pristine and irradiated MWCNT were filtrated using $45 \mu \mathrm{m}$ nylon membranes and the relative concentration of the metallic residues was calculated using pMWCNT as reference.

FTIR spectra were obtained using a Bruker EQUINOX 25 spectrometer using $\mathrm{KBr}$ disks as holders. Spectra were taken in the $4000-400 \mathrm{~cm}^{-1}$ range with $1 \mathrm{~cm}^{-1}$ resolution. Solid phases of MWCNT suspensions were analyzed.

TOC was measured using a high-temperature carbon analyzer (Shimadzu TOC 5000 A) using a calibration curve with potassium biphthalate standard. Standard solutions were run before each analysis to check for instrumental shifts.

Electrochemical assays were performed using a threeelectrode cell. A Pt foil was used as the counter electrode, a Pt wire with an exposed area of $4.7 \mathrm{~cm}^{2}$ as the working electrode, and a saturated calomel electrode (SCE) as the reference electrode. The Pt working electrode was mechanically polished with emery papers of 1000-2500 grit using water as the lubricant, rinsed with ultrapure water, and dried with nitrogen, followed by activation in $0.2 \mathrm{M} \mathrm{H}_{2} \mathrm{SO}_{4}$ by 15 voltamperometric cycles between -0.24 and $1.40 \mathrm{~V}$ at $100 \mathrm{mV}$ $\mathrm{s}^{-1}$. Potentiodynamic assays were performed in the -0.6 to 0.8 $\mathrm{V}$ potential range $\left(1 \mathrm{mV} \mathrm{s}^{-1}\right)$ in different electrolytes: SIM solution (control), $10 \mathrm{ppm}$ of pMWCNT suspended in SIM, HA-MWCNT suspended in SIM, and 10 ppm of Ir-MWCNT suspended in SIM. Each test was run in triplicate to verify the reproducibility of the data. In all cases, a potentiostatgalvanostat TEQ03 was used and the potential values were referred to the SCE.

4.6. Microbiological Assays. 4.6.1. Biofilm Formation. Biofilm assays were performed as described in our previous work with minor modifications. ${ }^{72}$ Briefly, biofilms were formed on sterilized glass slides that were immersed in the bacteriacontaining flask (Pseudomonas aeruginosa suspension $\mathrm{OD}^{590}=$ 0.5) parallel to the lateral walls. Diluted medium $[1 / 10$ nutrient broth $(\mathrm{NB})]$ used in previous works was employed to emulate natural conditions. ${ }^{73,74}$

The whole system was subsequently incubated at $31{ }^{\circ} \mathrm{C}$ for 1 h. Then, the slides were washed off with sterile phosphate buffer solution (PBS) and introduced into a multiwell plate. Each plate contained $1 \mathrm{~mL}$ of water with $10 \mathrm{ppm}$ of either pMWCNT, HA-MWCNT, or Ir-MWCNT. Pure water with 10 ppm of HA was used as control. The samples were incubated at $31{ }^{\circ} \mathrm{C}$ for $24 \mathrm{~h}$. After the incubation period, loosely adherent bacteria of the biofilms were washed off two times with sterile PBS. Biofilmed slides were then sonicated for $15 \mathrm{~min}$ in a sterile flask containing $1 \mathrm{~mL}$ of PBS to peel off the microbes, and the resulting suspension was diluted for bacterial counting in an agar plate.

4.6.2. SEM and Epifluorescence Microscopies. A similar scheme of biofilm formation was used to perform SEM observations. Previously, the biofilmed glasses were fixed using $2 \%$ glutaraldehyde solution and the dehydrated using different ethanol solutions, starting at concentrations close to $50 \%$ and finishing with absolute ethanol (99\%). Then, a final dehydration with critical $\mathrm{CO}_{2}$ and a coverage with $\mathrm{Au}$ were performed prior to the observation.

Statistical analysis of the distribution of the lengths of the bacteria growing in biofilms was made using images of SEM.

Bacterial adhesion and biofilm formation were also analyzed by epifluorescence microscopy after staining with acridine orange $(\mathrm{AO})$ following the procedure of a previous work. ${ }^{72}$ To this purpose, $P$. aeruginosa biofilms were formed on sterilized glass slides for $24 \mathrm{~h}$ as was described above. After the incubation period, the substrates with biofilms were rinsed with the PBS solution and dyed using AO (50 $\mu \mathrm{L}$ of the dye solution) and subsequently kept in the dark $(10 \mathrm{~min})$ at room temperature. Finally, the substrates were rinsed with sterile water and immediately observed using an epifluorescence microscope (Olympus BX 51, Olympus Corp., Tokyo, Japan). The microscope filter used was U-MWB2 (excitation 460-490 $\mathrm{nm}$ and emission $520 \mathrm{~nm}$ ), and the images were taken by an Olympus DP71 (Olympus Corp., Tokyo, Japan) color video camera connected to the microscope. Surface densities of bacteria or biofilms from digital images were determined using Image-Pro Plus software and were quantified as the percentage of area covered by bacteria over the total area of each image. Data were referred to the value of the control assayed.

\section{ASSOCIATED CONTENT}

\section{Supporting Information}

The Supporting Information is available free of charge at https://pubs.acs.org/doi/10.1021/acsomega.0c05114.

Scheme of the experimental procedure, statistical analysis of the size of bacteria growing in biofilms after being exposed to different types of MWCNT, epifluorescence microscopy of biofilm glasses stained with AO, and effect of MWCNT on biofilms after $\mathrm{HA}$ and irradiation treatments (Ir-HA-MWCNT) (PDF)

\section{AUTHOR INFORMATION}

\section{Corresponding Author}

Mónica Fernández Lorenzo de Mele - Instituto de Investigaciones Fisicoquímicas Teóricas y Aplicadas (INIFTA), CCT La Plata, CONICET, Facultad de Ciencias Exactas and Facultad de Ingeniería, UNLP, 1900 La Plata, Argentina; 이이.orid.o000-0002-8093-7551; Phone: 54 221 4257430; Email: mmele@inifta.unlp.edu.ar, fernandezlorenzom@hotmail.com; Fax: 542214254642

\section{Authors}

Damián Rodríguez Sartori - Instituto de Investigaciones Fisicoquímicas Teóricas y Aplicadas (INIFTA), CCT La Plata, CONICET, Facultad de Ciencias Exactas, UNLP, 1900 La Plata, Argentina

Marcos Bertuola - Instituto de Investigaciones Fisicoquímicas Teóricas y Aplicadas (INIFTA), CCT La Plata, CONICET, Facultad de Ciencias Exactas, UNLP, 1900 La Plata, Argentina 
Alejandro Miñán - Instituto de Investigaciones Fisicoquímicas Teóricas y Aplicadas (INIFTA), CCT La Plata, CONICET, Facultad de Ciencias Exactas, UNLP, 1900 La Plata, Argentina

Eduardo Gonik - Instituto de Investigaciones Fisicoquímicas Teóricas y Aplicadas (INIFTA), CCT La Plata, CONICET, Facultad de Ciencias Exactas, UNLP, 1900 La Plata, Argentina

Mónica C. Gonzalez - Instituto de Investigaciones Fisicoquímicas Teóricas y Aplicadas (INIFTA), CCT La Plata, CONICET, Facultad de Ciencias Exactas, UNLP, 1900 La Plata, Argentina; 이이. orcid.org/000-0003-32592111

Complete contact information is available at:

https://pubs.acs.org/10.1021/acsomega.0c05114

\section{Notes}

The authors declare no competing financial interest.

\section{ACKNOWLEDGMENTS}

D.R.S., M.B.,, and E.G. thank CONICET, Argentina, for their post-graduate studentships. M.C.G., M.F.L.d.M., and A.M. are research members of CONICET. The work was performed with funds of the grants PICT 2015-1266 and 2016-1424 from ANPCyT, PIP 0601, UNLP (11/X900), and CONICET (PUE 22920170100100CO).

\section{REFERENCES}

(1) Kim, Y. S.; Oh, J. Y.; Kim, J. H.; Shin, M. H.; Jeong, Y. C.; Sung, S. J.; Park, J.; Yang, S. J.; Park, C. R. Crucial Role of Oxidation Debris of Carbon Nanotubes in Subsequent End-Use Applications of Carbon Nanotubes. ACS Appl. Mater. Interfaces 2017, 9, 17552-17564.

(2) Cimbaluk, G. V.; Ramsdorf, W. A.; Perussolo, M. C.; Santos, H. K. F.; Da Silva De Assis, H. C.; Schnitzler, M. C.; Schnitzler, D. C.; Carneiro, P. G.; Cestari, M. M. Evaluation of Multiwalled Carbon Nanotubes Toxicity in Two Fish Species. Ecotoxicol. Environ. Saf. 2018, 150, 215-223.

(3) Tejral, G.; Panyala, N. R.; Havel, J. Carbon Nanotubes: Toxicological Impact on Human Health and Environment. J. Appl. Biomed. 2009, 7, 1-13.

(4) Wu, X. C.; Zhang, W. J.; Sammynaiken, R.; Meng, Q. H.; Yang, Q. Q.; Zhan, E.; Liu, Q.; Yang, W.; Wang, R. Non-Functionalized Carbon Nanotube Binding with Hemoglobin. Colloids Surf., B 2008, $65,146-149$.

(5) Song, Z.-M.; Wang, L.; Chen, N.; Cao, A.; Liu, Y.; Wang, H. Biological Effects of Agglomerated Multi-Walled Carbon Nanotubes. Colloids Surf., B 2016, 142, 65-73.

(6) Rodríguez Sartori, D.; Laura, M. L.; Magnacca, G.; Calza, P.; Laurenti, E.; Gonzalez, M. C. Multi-Walled Carbon Nanotubes Photochemistry: A Mechanistic View of the Effect of Impurities and Oxygen-Containing Surface Groups. Carbon 2018, 138, 161-168.

(7) Wang, F.; Yao, J.; Liu, H.; Liu, R.; Chen, H.; Yi, Z.; Yu, Q.; Ma, L.; Xing, B. $\mathrm{Cu}$ and $\mathrm{Cr}$ Enhanced the Effect of Various Carbon Nanotubes on Microbial Communities in an Aquatic Environment. J. Hazard. Mater. 2015, 292, 137-145.

(8) Mocan, T.; Matea, C. T.; Pop, T.; Mosteanu, O.; Buzoianu, A. D.; Suciu, S.; Puia, C.; Zdrehus, C.; Iancu, C.; Mocan, L. Carbon Nanotubes as Anti-Bacterial Agents. Cell. Mol. Life Sci. 2017, 74, 3467-3479.

(9) Mohanty, A.; Tan, C. H.; Cao, B. Impacts of Nanomaterials on Bacterial Quorum Sensing: Differential Effects on Different Signals. Environ. Sci.: Nano 2016, 3, 351-356.

(10) Zhu, B.; Xia, X.; Xia, N.; Zhang, S.; Guo, X. Modification of Fatty Acids in Membranes of Bacteria: Implication for an Adaptive Mechanism to the Toxicity of Carbon Nanotubes. Environ. Sci.: Nano 2014, 48, 4086-4095.
(11) Du, J.; Wang, S.; You, H.; Zhao, X. Understanding the Toxicity of Carbon Nanotubes in the Environment Is Crucial to the Control of Nanomaterials in Producing and Processing and the Assessment of Health Risk for Human: A Review. Environ. Toxicol. Pharmacol. 2013, $36,451-462$.

(12) Hai, R.; Wang, Y.; Wang, X.; Du, Z.; Li, Y. Impacts of Multiwalled Carbon Nanotubes on Nutrient Removal from Wastewater and Bacterial Community Structure in Activated Sludge. PLoS One 2014, 9, No. e107345.

(13) Lan, J.; Gou, N.; Gao, C.; He, M.; Gu, A. Z. Comparative and Mechanistic Genotoxicity Assessment of Nanomaterials via a Quantitative Toxicogenomics Approach across Multiple Species. Environ. Sci.: Nano 2014, 48, 12937-12945.

(14) Zhu, S.; Zhu, B.; Huang, A.; Hu, Y.; Wang, G.; Ling, F. Toxicological Effects of Multi-Walled Carbon Nanotubes on Saccharomyces Cerevisiae: The Uptake Kinetics and Mechanisms and the Toxic Responses. J. Hazard. Mater. 2016, 318, 650-662.

(15) Ghosh, M.; Chakraborty, A.; Bandyopadhyay, M.; Mukherjee, A. Multi-walled carbon nanotubes (MWCNT): Induction of DNA damage in plant and mammalian cells. J. Hazard. Mater. 2011, 197, $327-336$

(16) Flemming, H.-C.; Neu, T. R.; Wozniak, D. J. The EPS Matrix: The "House of Biofilm Cells". J. Bacteriol. 2007, 189, 7945-7947.

(17) Zardini, H. Z.; Amiri, A.; Shanbedi, M.; Maghrebi, M.; Baniadam, M. Enhanced Antibacterial Activity of Amino AcidsFunctionalized Multi Walled Carbon Nanotubes by a Simple Method. Colloids Surf., B 2012, 92, 196-202.

(18) Bai, Y.; Park, I. S.; Lee, S. J.; Wen, P. S.; Bae, T. S.; Lee, M. H. Effect of AOT-Assisted Multi-Walled Carbon Nanotubes on Antibacterial Activity. Colloids Surf., B 2012, 89, 101-107.

(19) Rajavel, K.; Gomathi, R.; Manian, S.; Rajendra Kumar, R. T. In Vitro Bacterial Cytotoxicity of CNTs: Reactive Oxygen Species Mediate Cell Damage Edges over Direct Physical Puncturing. Langmuir 2014, 30, 592-601.

(20) Chi, M.-F.; Wu, W.-L.; Du, Y.; Chin, C.-J. M.; Lin, C.-C. Inactivation of Escherichia Coli Planktonic Cells by Multi-Walled Carbon Nanotubes in Suspensions: Effect of Surface Functionalization Coupled with Medium Nutrition Level. J. Hazard. Mater. 2016, $318,507-514$.

(21) Rodrigues, D. F.; Elimelech, M. Toxic Effects of Single-Walled Carbon Nanotubes in the Development of E. coli Biofilm. Environ. Sci. Technol. 2010, 44, 4583-4589.

(22) Goodwin, D. G.; Xia, Z.; Gordon, T. B.; Gao, C.; Bouwer, E. J.; Fairbrother, D. H. Biofilm development on carbon nanotube/polymer nanocomposites. Environ. Sci.: Nano 2016, 3, 545-558.

(23) Lawrence, J. R.; Swerhone, G. D. W.; Dynes, J. J.; Hitchcock, A P.; Korber, D. R. Complex Organic Corona Formation on Carbon Nanotubes Reduces Microbial Toxicity by Suppressing Reactive Oxygen Species Production. Environ. Sci.: Nano 2016, 3, 181-189.

(24) Lin, D.; Li, T.; Yang, K.; Wu, F. The Relationship between Humic Acid (HA) Adsorption on and Stabilizing Multiwalled Carbon Nanotubes (MWNTs) in Water: Effects of HA, MWNT and Solution Properties. J. Hazard. Mater. 2012, 241-242, 404-410.

(25) Korotta-Gamage, S. M.; Sathasivan, A. A Review: Potential and Challenges of Biologically Activated Carbon to Remove Natural Organic Matter in Drinking Water Purification Process. Chemosphere 2017, 167, 120-138.

(26) Miao, Y.; Wu, C.; Guan, L. Enrichment of Semiconducting Single-Walled Carbon Nanotubes by Simple Equipment and Solar Radiation. Nanotechnology 2019, 30, 06LT01.

(27) Petersen, E. J.; Flores-cervantes, D. X.; Bucheli, T. D.; Elliott, L. C. C.; Fagan, J. A.; Gogos, A.; Hanna, S.; Kägi, R.; Mansfield, E.; Bustos, A. R. M.; Plata, D. L.; Reipa, V.; Westerhoff, P.; Winchester, M. R. Quantification of Carbon Nanotubes in Environmental Matrices: Current Capabilities, Case Studies, and Future Prospects. Environ. Sci. Technol. 2016, 50, 4587-4605.

(28) Lew, S.; Glińska-Lewczuk, K.; Lew, M. The Effects of Environmental Parameters on the Microbial Activity in Peat-Bog Lakes. PLoS One 2019, 14, No. e0224441. 
(29) Kang, S.; Herzberg, M.; Rodrigues, D. F.; Elimelech, M. Antibacterial Effects of Carbon Nanotubes: Size Does Matter! Langmuir 2008, 24, 6409-6413.

(30) Baysal, A.; Saygin, H.; Ustabasi, G. S. Influence of Environmental Media on Carbon Nanotubes and Graphene Nanoplatelets towards Bacterial Toxicity. Arch. Environ. Prot. 2018, 44, 8598.

(31) Hiemenz, P. C.; Hiemenz, P. C. Principles of Colloid and Surface Chemistry; Marcel Dekker: New York, 1986; Vol. 188.

(32) Purmalis, O. Comparative study of peat humic acids by using UV Spectroscopy. 1st Annual International Interdisciplinary Conference, 2013.

(33) Lee, B.-M.; Seo, Y.-S.; Hur, J. Investigation of Adsorptive Fractionation of Humic Acid on Graphene Oxide Using Fluorescence EEM-PARAFAC. Water Res. 2015, 73, 242-251.

(34) Hyung, H.; Kim, J.-H. Natural Organic Matter (NOM) Adsorption to Multi-Walled Carbon Nanotubes: Effect of NOM Characteristics and Water Quality Parameters. Environ. Sci. Technol. 2008, 42, 4416-4421.

(35) Sadtler Research Laboratories, W.W., Simons, S.R., Laboratories. The Sadtler Handbook of Infrared Spectra; Sadtler Research Laboratories: Philadelphia, 1978.

(36) Koesnarpadi, S.; Santosa, S. J.; Siswanta, D.; Rusdiarso, B. Synthesis and Characterizatation of Magnetite Nanoparticle Coated Humic Acid (Fe3O4/HA). Procedia Environ. Sci. 2015, 30, 103-108.

(37) Djebaili, K.; Mekhalif, Z.; Boumaza, A.; Djelloul, A. XPS, FTIR, EDX, and XRD Analysis of Al2O3 Scales Grown on PM2000 Alloy. J. Spectrosc. 2015, 2015, 1-16.

(38) Martin, H. B.; Smith, B. A.; Angus, J. C.; Landau, U.; Anderson, A. B. Boron-Doped Diamond Films for Electrochemical Applications. MRS Proc. 1998, 555, 217.

(39) Bian, S.-W.; Mudunkotuwa, I. A.; Rupasinghe, T.; Grassian, V. $\mathrm{H}$. Aggregation and Dissolution of $4 \mathrm{~nm} \mathrm{ZnO}$ Nanoparticles in Aqueous Environments: Influence of $\mathrm{pH}$, Ionic Strength, Size, and Adsorption of Humic Acid. Langmuir 2011, 27, 6059-6068.

(40) Yang, K.; Lin, D.; Xing, B. Interactions of Humic Acid with Nanosized Inorganic Oxides. Langmuir 2009, 25, 3571-3576.

(41) Giasuddin, A. B. M.; Kanel, S. R.; Choi, H. Adsorption of Humic Acid onto Nanoscale Zerovalent Iron and Its Effect on Arsenic Removal. Environ. Sci. Technol. 2007, 41, 2022-2027.

(42) Martyniuk, H.; Więckowska, J. Adsorption of Metal Ions on Humic Acids Extracted from Brown Coals. Fuel Process. Technol. 2003, 84, 23-36.

(43) Yang, S.; Li, L.; Pei, Z.; Li, C.; Shan, X.-q.; Wen, B.; Zhang, S.; Zheng, L.; Zhang, J.; Xie, Y.; Huang, R. Effects of Humic Acid on Copper Adsorption onto Few-Layer Reduced Graphene Oxide and Few-Layer Graphene Oxide. Carbon 2014, 75, 227-235.

(44) Clarke, N.; Danielsson, L.-G.; Sparén, A. Studies of Aluminium Complexation to Humic and Fulvic Acids Using a Method for the Determination of Quickly Reacting Aluminium. Water, Air, Soil Pollut. 1995, 84, 103-116.

(45) Berggren, D.; Mulder, J. The Role of Organic Matter in Controlling Aluminum Solubility in Acidic Mineral Soil Horizons. Geochim. Cosmochim. Acta 1995, 59, 4167-4180.

(46) Lobartini, J. C.; Tan, K. H.; Pape, C. Dissolution of Aluminum and Iron Phosphate by Humic Acids. Commun. Soil Sci. Plant Anal. 1998, 29, 535-544.

(47) Harrison, J. J.; Ceri, H.; Yerly, J.; Stremick, C. A.; Hu, Y.; Martinuzzi, R; Turner, R. J. The Use of Microscopy and ThreeDimensional Visualization to Evaluate the Structure of Microbial Biofilms Cultivated in the Calgary Biofilm Device. Biol. Proced. Online 2006, 8, 194-215.

(48) Wijesinghe, G.; Dilhari, A.; Gayani, B.; Kottegoda, N.; Samaranayake, L.; Weerasekera, M. Influence of Laboratory Culture Media on in Vitro Growth, Adhesion, and Biofilm Formation of Pseudomonas aeruginosa and Staphylococcus aureus. Med. Princ. Pract. 2019, 28, 28-35.
(49) Zhou, S.; Chen, S.; Yuan, Y.; Lu, Q. Influence of Humic Acid Complexation with Metal Ions on Extracellular Electron Transfer Activity. Sci. Rep. 2015, 5, 17067.

(50) Piña, R. G.; Cervantes, C. Microbial Interactions with Aluminium. BioMetals 1996, 9, 311-316.

(51) Verneuil, L.; Silvestre, J.; Randrianjatovo, I.; Marcato-Romain, C.-E.; Girbal-Neuhauser, E.; Mouchet, F.; Flahaut, E.; Gauthier, L.; Pinelli, E. Double Walled Carbon Nanotubes Promote the Overproduction of Extracellular Protein-like Polymers in Nitzschia Palea: An Adhesive Response for an Adaptive Issue. Carbon 2015, 88, 113125.

(52) Wang, Q.; Kang, F.; Gao, Y.; Mao, X.; Hu, X. Sequestration of Nanoparticles by an EPS Matrix Reduces the Particle-Specific Bactericidal Activity. Sci. Rep. 2016, 6, 21379.

(53) González, A. G.; Shirokova, L. S.; Pokrovsky, O. S.; Emnova, E. E.; Martínez, R. E.; Santana-Casiano, J. M.; González-Dávila, M.; Pokrovski, G. S. Adsorption of Copper on Pseudomonas aureofaciens: Protective Role of Surface Exopolysaccharides. J. Colloid Interface Sci. 2010, 350, 305-314.

(54) Zeng, W.; Li, F.; Wu, C.; Yu, R.; Wu, X.; Shen, L.; Liu, Y.; Qiu, G.; Li, J. Role of Extracellular Polymeric Substance (EPS) in Toxicity Response of Soil Bacteria Bacillus Sp. S3 to Multiple Heavy Metals. Bioprocess Biosyst. Eng. 2020, 43, 153-167.

(55) Nocelli, N.; Bogino, P.; Banchio, E.; Giordano, W. Roles of Extracellular Polysaccharides and Biofilm Formation in Heavy Metal Resistance of Rhizobia. Materials 2016, 9, 418.

(56) Tourney, J.; Ngwenya, B. T. The Effect of Ionic Strength on the Electrophoretic Mobility and Protonation Constants of an EPSProducing Bacterial Strain. J. Colloid Interface Sci. 2010, 348, 348354.

(57) Krishnamurthi, V. R.; Chen, J.; Wang, Y. Silver Ions Cause Oscillation of Bacterial Length of Escherichia coli. Sci. Rep. 2019, 9, 11745 .

(58) Flemming, H.-C.; Wingender, J. The Biofilm Matrix. Nat. Rev. Microbiol. 2010, 8, 623-633.

(59) Colvin, K. M.; Irie, Y.; Tart, C. S.; Urbano, R.; Whitney, J. C.; Ryder, C.; Howell, P. L.; Wozniak, D. J.; Parsek, M. R. The Pel and Psl Polysaccharides Provide Pseudomonas aeruginosa Structural Redundancy within the Biofilm Matrix. Environ. Microbiol. 2012, 14, 1913-1928.

(60) Periasamy, S.; Nair, H. A. S.; Lee, K. W. K.; Ong, J.; Goh, J. Q. J.; Kjelleberg, S.; Rice, S. A. Pseudomonas aeruginosa PAO1 Exopolysaccharides Are Important for Mixed Species Biofilm Community Development and Stress Tolerance. Front. Microbiol. 2015, 6, 851 .

(61) Billings, N.; Ramirez Millan, M.; Caldara, M.; Rusconi, R.; Tarasova, Y.; Stocker, R.; Ribbeck, K. The Extracellular Matrix Component Psl Provides Fast-Acting Antibiotic Defense in Pseudomonas aeruginosa Biofilms. PLoS Pathog. 2013, 9, No. e1003526.

(62) Baum, M. M.; Kainović, A.; O'Keeffe, T.; Pandita, R.; McDonald, K.; Wu, S.; Webster, P. Characterization of Structures in Biofilms Formed by a Pseudomonas fluorescens Isolated from Soil. BMC Microbiol. 2009, 9, 103.

(63) Young, K. D. The Selective Value of Bacterial Shape. Microbiol. Mol. Biol. Rev. 2006, 70, 660-703.

(64) Steinberger, R. E.; Allen, A. R.; Hansma, H. G.; Holden, P. A. Elongation Correlates with Nutrient Deprivation in Pseudomonas aeruginosa Unsaturated Biofilms. Microb. Ecol. 2002, 43, 416-423.

(65) Cefalì, E.; Patanè, S.; Arena, A.; Saitta, G.; Guglielmino, S.; Cappello, S.; Nicolò, M.; Allegrini, M. Morphologic Variations in Bacteria under Stress Conditions: Near-Field Optical Studies. Scanning 2002, 24, 274-283.

(66) Cesar, S.; Huang, K. C. Thinking Big: The Tunability of Bacterial Cell Size. FEMS Microbiol. Rev. 2017, 41, 672-678.

(67) Liu, X.; Cai, J.; Chen, H.; Zhong, Q.; Hou, Y.; Chen, W.; Chen, W. Antibacterial Activity and Mechanism of Linalool against Pseudomonas aeruginosa. Microb. Pathog. 2020, 141, 103980. 
(68) Dong, X.; Yang, L. Inhibitory Effects of Single-Walled Carbon Nanotubes on Biofilm Formation from Bacillus anthracis Spores. Biofouling 2014, 30, 1165-1174.

(69) Guo, Z.; Xie, C.; Zhang, P.; Zhang, J.; Wang, G.; He, X.; Ma, Y.; Zhao, B.; Zhang, Z. Toxicity and Transformation of Graphene Oxide and Reduced Graphene Oxide in Bacteria Biofilm. Sci. Total Environ. 2017, 580, 1300-1308.

(70) Booth, S. C.; Weljie, A. M.; Turner, R. J. Metabolomics reveals differences of metal toxicity in cultures of Pseudomonas pseudoalcaligenes KF707 grown on different carbon sources. Front. Microbiol. 2015, 6, 827.

(71) Manzano, M.; Zabala, M. E. El Fondo Químico Natural Del Sistema Acuífero de La Cuenca Del Río Matanza-Riachuelo. Conference Paper, 2012; September, p 222.

(72) Bertuola, M.; Miñán, A.; Grillo, C. A.; Cortizo, M. C.; Fernández Lorenzo de Mele, M. A. Corrosion Protection of AZ31 Alloy and Constrained Bacterial Adhesion Mediated by a Polymeric Coating Obtained from a Phytocompound. Colloids Surf., B 2018, 172, 187-196.

(73) Miñán, A.; Lorente, C.; Ipiña, A.; Thomas, A. H.; Fernández Lorenzo de Mele, M.; Schilardi, P. L. Photodynamic Inactivation Induced by Carboxypterin: A Novel Non-Toxic Bactericidal Strategy against Planktonic Cells and Biofilms of Staphylococcus aureus. Biofouling 2015, 31, 459-468.

(74) Tosato, M. G.; Schilardi, P.; Lorenzo de Mele, M. F.; Thomas, A. H.; Lorente, C.; Miñán, A. Synergistic Effect of Carboxypterin and Methylene Blue Applied to Antimicrobial Photodynamic Therapy against Mature Biofilm of Klebsiella Pneumoniae. Heliyon 2020, 6, No. e03522. 